\title{
Temperature predicts the maximum tree-species richness and water and frost shape the residual variation
}

\author{
Ricardo A. Segovia ${ }^{1}$ \\ ${ }^{1}$ Instituto de Ecología y Biodiversidad (www.ieb-chile.cl), Santiago, Chile. \\ * segoviacortes@gmail.com
}

\section{Abstract}

The kinetic hypothesis of biodiversity proposes that temperature is the main driver of variation in species richness, given its exponential effect on biological activity and, potentially, on rates of diversification. However, limited support for this hypothesis has been found to date. I tested the fit of this model on the variation of tree-species richness along a continuous latitudinal gradient in the Americas. I found that the kinetic hypothesis accurately predicts the upper bound of the relationship between the inverse of mean annual temperature $(1 / k \mathrm{~K})$ and the natural logarithm of species richness, at a broad scale. In addition, I found that water availability and the number of days with freezing temperatures organize a part of the residual variation of the upper bound model. The finding of the model fitting on the upper bound rather than on the mean values suggest that the kinetic hypothesis is modeling the variation of the potential maximum species richness per unit of temperature. Likewise, the distribution of the residuals of the upper bound model in function of the number of days with freezing temperatures suggest the importance of environmental thresholds rather than gradual variation driving the observable variation in species richness. 


\section{Introduction}

While correlations between species richness and environmental variables

have been widely documented [Wright, 1983, Currie and Paquin,

1987, Adams and Woodward, 1989, Stephenson, 1990, O’Brien,

1993, O’Brien, 1998, Kreft and Jetz, 2007, Hawkins et al., 2003, Currie et al.,

2004, Jetz and Rahbek, 2002, Mutke and Barthlott, 2005, Mutke et al.,

2001, Francis and Currie, 2003, Field et al., 2005], a general law or even a

single, coherent explanation for these correlations is still elusive Gaston,

2000, Rohde, 1992, Brown, 2014]. The most formal and testable hypothesis

to mechanistically relate species richness to environmental parameters is

the kinetic model, which forms part of the framework of the "Metabolic

Theory of Ecology" [Brown, 2014]. Under this hypothesis, temperature

would be the main driver of variation in species richness, given its effect on

the activation of enzymatic reactions, the rates of energy flux and thus,

potentially, on rates of ecological interaction and diversification Rohde, 1992, Allen et al., 2002, Brown et al., 2004, Brown, 2014. Therefore, a

predictive model derived from the exponential Boltzmann temperature

relationship has been proposed and tested across different taxa Allen et al., 2002, Brown et al., 2004]. However, subsequent studies at global Kreft and Jetz, 2007] and regional [Hawkins et al., 2007a, Algar et al., 2007] scales show no support for two of the main predictions of the model: 1) a linear relationship between species richness and temperature Allen et al., 2002, Allen et al., 2007, Brown et al., 2004, and 2) a negative slope of $\sim 0.65$ between the inverse of temperature $(1.000 / \mathrm{kK})$ and the natural logarithm of species richness Brown et al., 2004.

To predict species richness gradients, the kinetic model connects two previously recognized relationships: the temperature dependence of the metabolic rate Gillooly et al., 2001] and the energetic-equivalence rule of population energy use Enquist et al., 1998. Temperature controls metabolism through its effects on rates of biochemical reactions. Reaction kinetics vary exponentially with temperature according to the Boltzmann's factor $e^{-E i / k T}$, where $\mathrm{T}$ is the absolute temperature (in degrees $\mathrm{K}$ ), $E$ is the 
activation energy, and $k$ is Boltzmann's constant Gillooly et al., 2001. 33 The increase in metabolic rate results in turn in higher energy use per $\quad 34$ individual, but the population energy use should remain approximately 35 constant Enquist et al., 1998. Thus, fewer individuals per population are 36 expected towards warmer environments Brown et al., 2004. Considering 37 that the total number of individuals in a community is largely independent $\quad 38$ of latitudinal gradients in temperature when no other environmental constraints are influencing it (i.e., water deficit) Enquist and Niklas, 2001, Currie et al., 2004, the result is higher species richness in communities from warmer environments Allen et al., 2002. Moreover, the kinetic model suggests that in addition of the direct effect of energy use increasing, coevolutionary interactions associated with species coexistence generate and maintain even higher biodiversity towards warmer environments Brown, 2014.

In addition to temperature, the variation in species richness has also been related to water availability, often measured as mean annual precipitation Wright, 1983, Currie, 1991. Therefore, the effect of water availability could explain the failure of previous studies to support the temperature dependence of species richness across different environmental arrangements [Currie, 2007]. Currie (2007) Currie, 2007 hypothesized that the model proposed by Allen et al. (2002) Allen et al., 2002 only would fit on the upper bound of the relationship between species richness and mean annual temperature (MAT) in plants, but cannot explain the \$species richness variation on its mean values. Allen et al. (2007) Allen et al., 2007 agree with this, and suggest that the residual variation below the proposed upper bound fit would be associated with variation in the total number of individuals in a community due, mainly, to water deficit. Indeed, statistical models show that forests can reach their maximum species richness when high annual energy input is combined with high water availability throughout the year Kreft and Jetz, 2007. However, limits rather than mean temperature also could explain part of the residual variation of the kinetic model. The metabolism-temperature dependence is valid within the limited range of "biologically relevant" temperatures 
between approximately $0^{\circ}$ and $40^{\circ} \mathrm{C}$. Near $0^{\circ} \mathrm{C}$, metabolic reactions cease $\quad{ }_{66}$ due to the phase transition associated with freezing water Gillooly et al., 67 2001, Brown et al., 2004. Thus, events of freezing temperatures can interrupt the general effect of environmental temperature on biochemical $\quad 69$ reactions and energy use, modifying the expected species richness beyond 70 the effect of mean values (i.e., MAT).

The original proposal of the kinetic model and the posterior empirical approaches have only tested the central tendency of the variation in species richness Allen et al., 2002, Brown et al., 2004, Hawkins et al., 2007a, Hawkins et al., 2007b, Algar et al., 2007, Kreft and Jetz, 2007,

rather than the upper bound of the relationship. In order to evaluate the predictions of the kinetic model around the upper bound of the temperature-dependent variation in species richness, I analyzed 10,721 inventories of tree species across a broad, continuous latitudinal gradient in the Americas (between $49^{\circ} \mathrm{N}$ and $55^{\circ} \mathrm{S}$ in North, Central and South America). I tested the predictions of linearity and a negative slope $(\sim 0.65)$ using regression models throughout the upper quantiles of species richness variation. To test the linearity of the relationship between the inverse of temperature $(1,000 / \mathrm{kK})$ and the upper quantiles of the natural logarithm of species richness, I assessed if segmented models, that allow for a breakpoints in the slope at some point over the range of the explanatory variable, provided better statistical fits than linear models. Thus, I compared the slopes of linear versus segmented models above the mean of the relationship $(55 \%, 65 \%, 75 \%, 85 \%, 95 \%$ quantiles $)$. In addition, I explored the influence of the previously hypothesized environmental drivers (i.e., climatic water deficit and freezing temperatures) on the variation of the residuals of quantile regressions.

As increasingly higher quantiles are examined (i.e. moving from 55\% quantiles to $95 \%$ quantiles), the statistical relationship between temperature $(1,000 / \mathrm{kK})$ and the natural logarithm of species richness 

segmented models reach over $\mathrm{R} 1=0.7$ at $95 \%$ quantile (see R1 statistic, Table 1). Although segmented models are more robust in all of the quantiles analyzed (see SIC, Table 1), the slopes in the segmented models towards the upper bound are not significantly different (Table 1, p-values greater to 0.05 to the test of the null hypothesis, slope $1=$ slope 2 ).

Furthermore, towards the very upper bound (quantile $85 \%$ and 95\%) both slopes are negatives, while in 55\%, 65\% and 75\%, the first slope is positive. Therefore, I cannot reject a linear, negative relationship towards the upper bound, where the models fit the better (Table 1, Fig. 1).

Table 1 Quantile models across the upper bound of the relationship between the inverse of temperature $(1,000 / \mathrm{kK})$ and the natural logarithm of species richness. R1 statistic is provided as a measure of the goodness of fit of the different models and the Schwartz's Information Criteria (SIC) as a relative quality measurement for linear and segmented models (for details, see Material and Methods). Slope values for linear and segmented quantile regressions (slope 1 and slope 2) are also provided. Finally, the p-value column means the results of the $t$ tests comparing if both slopes in the segmented models are significantly different ( $\mathrm{p}$-values $<0.05)$.

\begin{tabular}{|c|c|c|c|c|c|c|c|c|}
\hline Quantile & $\begin{array}{l}\mathrm{R} 1 \\
\text { linear }\end{array}$ & $\begin{array}{l}\text { R1 } \\
\text { segemented }\end{array}$ & $\begin{array}{l}\text { Linear } \\
\text { Slope }\end{array}$ & $\begin{array}{l}\text { Segmented } \\
\text { Slope } 1\end{array}$ & $\begin{array}{l}\text { Segmented } \\
\text { Slope } 2\end{array}$ & $\mathrm{p}$-value & $\begin{array}{l}\text { SIC } \\
\text { (linear) }\end{array}$ & $\begin{array}{l}\text { SIC } \\
\text { (segmented) }\end{array}$ \\
\hline $55 \%$ & 0.24 & 0.01 & -0.781 & 0.299 & -1.444 & 0.041 & 29117.46 & 27895.73 \\
\hline $65 \%$ & 0.24 & 0.07 & -0.789 & 0.306 & -1.458 & 0.039 & 29206.52 & 27986.76 \\
\hline $75 \%$ & 0.31 & 0.2 & -0.823 & 0.147 & -1.312 & 0.072 & 29599.82 & 28520.47 \\
\hline $85 \%$ & 0.46 & 0.43 & -0.808 & -0.194 & -1.011 & 0.207 & 30390.64 & 29279.77 \\
\hline $95 \%$ & 0.75 & 0.77 & -0.661 & -0.236 & -1.008 & 0.22 & 32444.54 & 30946.64 \\
\hline
\end{tabular}

I found that the negative linear slope of $\sim 0.65$, proposed by Brown $\quad 114$ et al. (2004) Brown et al., 2004 is reached around the 95\% quantile 115 (Table 1, Fig. 1). Instead, those linear model in lower quantiles present $\quad 116$ more pronounced slope than expected by the kinetic model (Table 1, Fig. ${ }_{117}$ 1). On the other hand, segmented models are far from the predicted range ${ }_{118}$ of slopes put forth by Brown et al. (2004) (Table 1). 


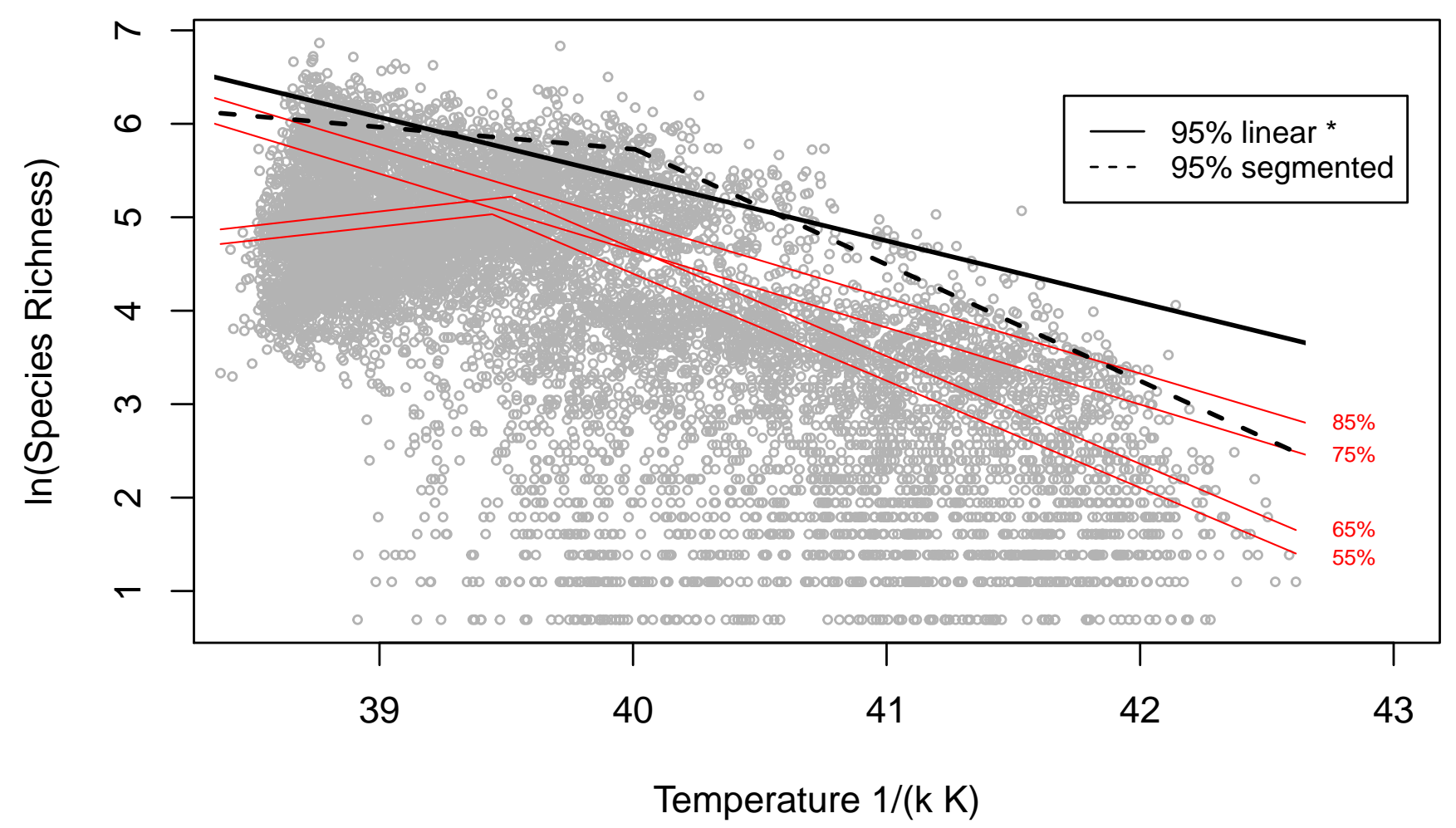

Fig.1 Effects of the inverse of the Mean Annual Temperature (MAT) on log-transformed species richness of trees in the Americas. Black lines represent the model fit at 95\% quantile for a linear regression (continuous) and for a one-breakpoint segmented regression (dashed). The red lines represents the best supported model (linear or segmented) in 55\%,65\%,75\% and $85 \%$ quantiles.

The temperature dependence of species richness at the upper bound analyzed by biomes shows that the linear slopes are mostly different than the expected by the model (Fig. 2). Slopes for the $95 \%$ quantile model from tropical biomes are farther away of the expected values than those from temperate biomes (Fig. 2). Likewise, dry biomes present the most $\quad{ }_{129}$ different slopes according to the expected under the kinetic model. $\quad 130$ Actually, slopes in dry biomes tend to be positive rather than negative, i.e., 131 they show a greater potential species richness towards relatively colder $\quad{ }_{132}$ areas within "Tropical \& Subtropical Grassland, Savannas Shrublands", ${ }_{133}$ "Tropical \& Subtropical Dry Boroadleaf Forests" and "Mediterranean $\quad 134$ Forests, Woodlands and Scrub" (Fig. 2). The closest slopes to the 135 expected by the kinetic model are found in "Temperate Grasslands, $\quad 136$ Savannas \& Shrublands" and "Temperate Conifer Forests" (Fig. 2). 

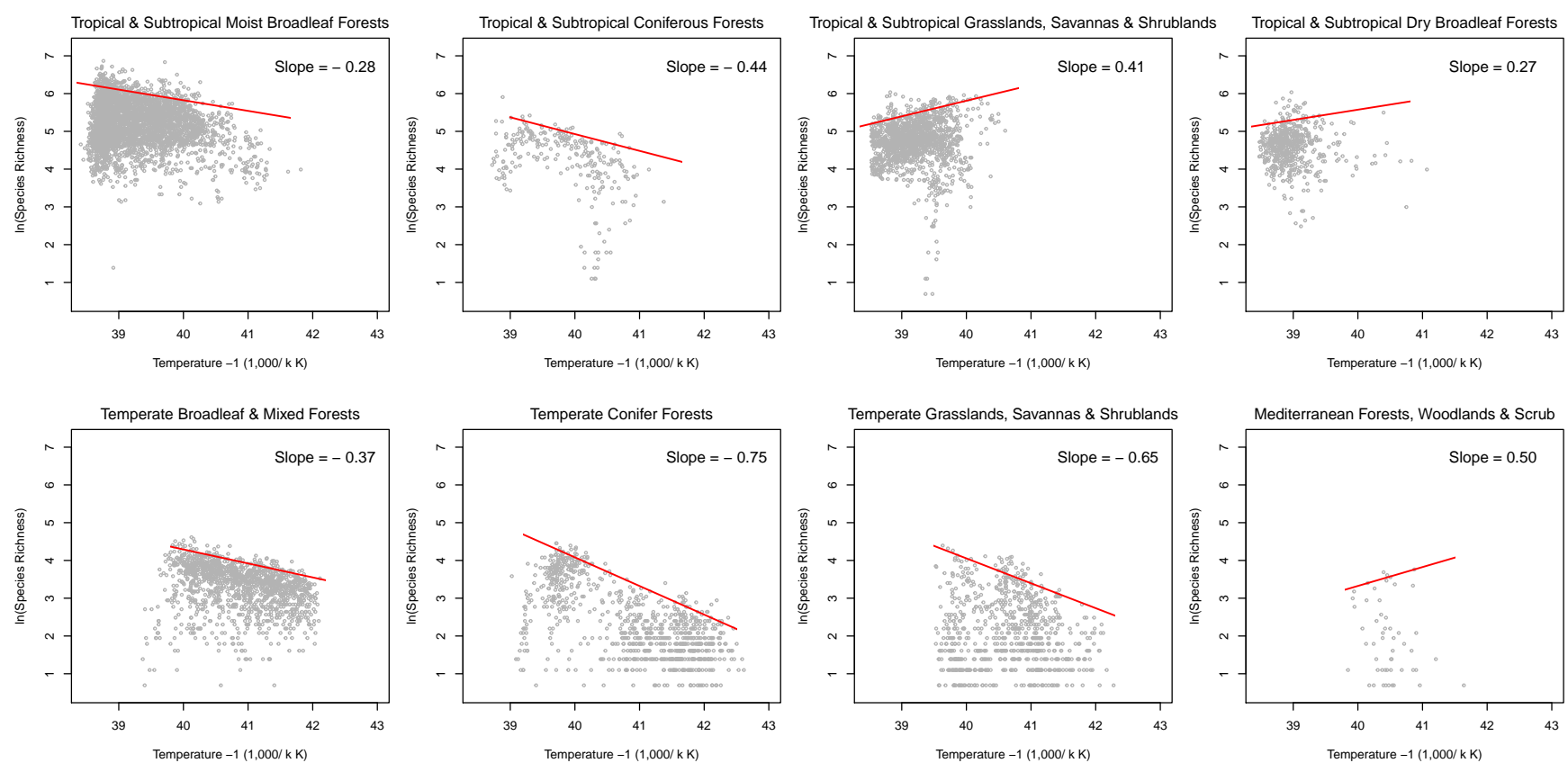

Fig.2 Quantile 95\% model for the main biomes in the Americas.

In a general view, the spatial distribution of the residual variation in ${ }_{140}$ the upper bound model shows that sites with low species richness are $\quad{ }_{141}$ farther away from the theoretical predictions than species-rich sites (Fig. ${ }_{142}$ $3)$. Sites with residuals lower than -1.5 tend to be concentrated preferentially in the northern and southern extratropics, subtropics and dry tropics (Fig. 3). In a biome-organized perspective, the residual variation in the $95 \%$ quantile model is more negative on average in temperate than in tropical biomes (Fig. 4). Likewise, sites from tropical wet biomes tend to be closer to the upper bound model than sites from tropical dry, subtropical and extratropical environments (Fig. 4). 

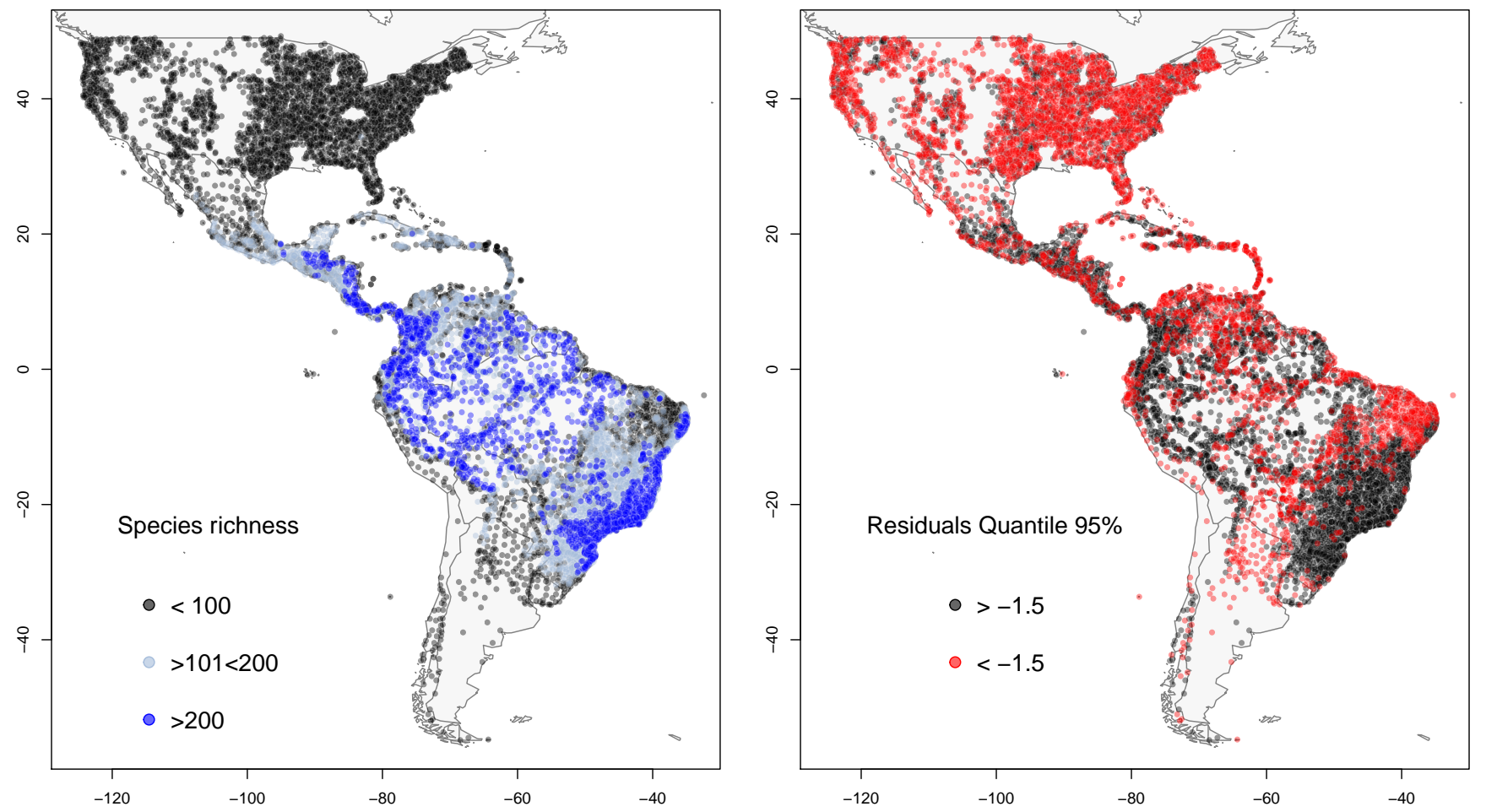

Fig.3 Geographic distribution of the species richness variation and the residual variation of the quantile 95\% model. A) Species richness across the 10,721 tree assemblages. Black dots show those assemblages with less than 100 species. Light-blue dots show those assemblages with a number of species between 101 and 200. And, blue dots show assemblages with more than 201 species. B) Residual variation from the upper bound model for the kinetic hypothesis. Black dots show those assemblages with more negative residual variation, and red dots those assemblages with a less negative residual variation.

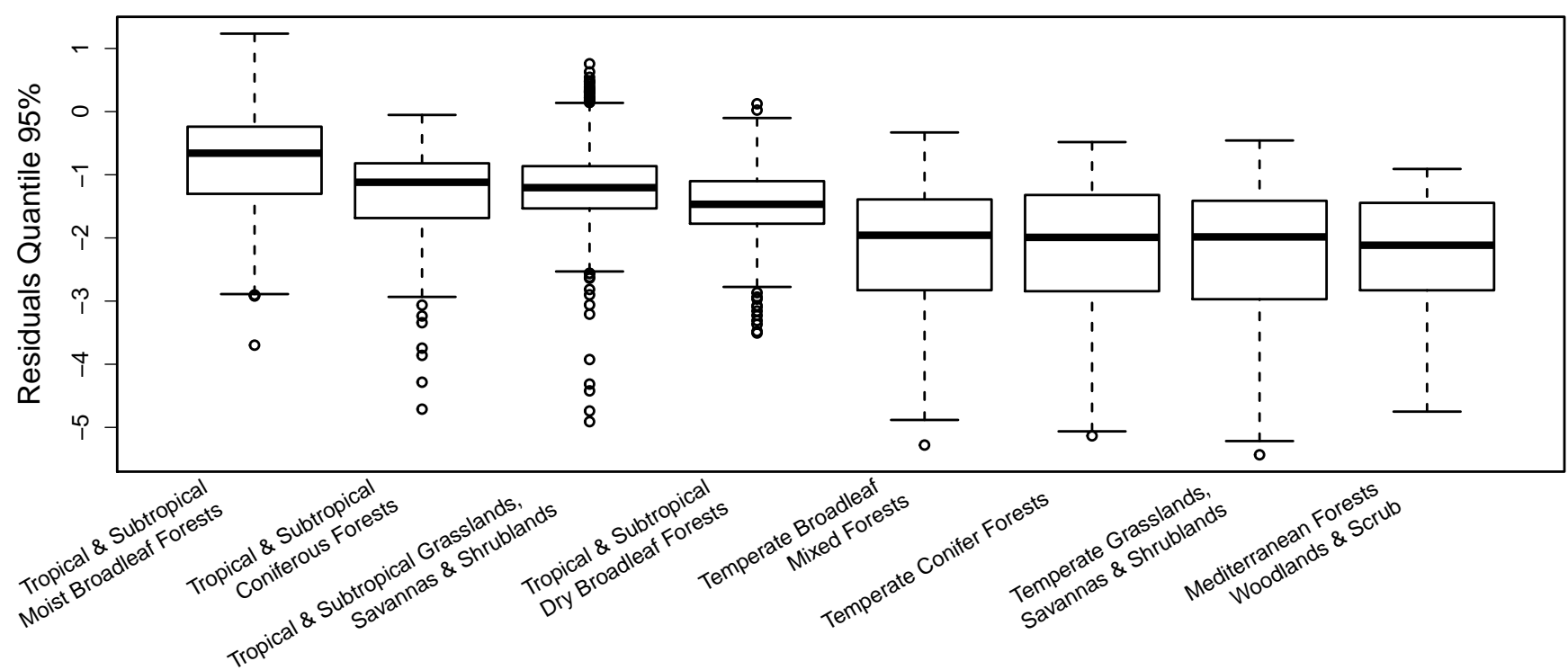

Fig.4 Residual variation of the quantile 95\% model across the main biomes in the Americas. Biome partition of the dataset is based on the ecorregions and biomes described by Olson et al. (2001) Olson et al., 2001. 
Water availability and presence of freezing temperatures affect the $\quad{ }_{161}$ residual variation around the upper bound of the kinetic model for the $\quad{ }_{162}$ temperature dependence of species richness (Fig. 5). Residual variation 163 tends to increase (i.e. more negative residuals) towards environments with 164 higher Climatic Water Deficit, indicated by more negative values (Fig. 5a), 165 and with greater exposure to freezing temperatures (Fig. 5b). While the ${ }_{166}$ effect of water deficit shows a relatively gradual change, the effect of $\quad 167$ freezing temperatures suggests a threshold effect (Fig. 5). Those sites with ${ }_{168}$ more than $\sim 1,000$ days with freezing temperatures during the last $117 \quad 169$ years (i.e., greater than $\sim 10$ days on average per year) tend to be farther 170 away of the predicted model for the $95 \%$ quantile than those sites with less than 10 days per year subject to freezing temperatures (Fig. 5b).

171
172
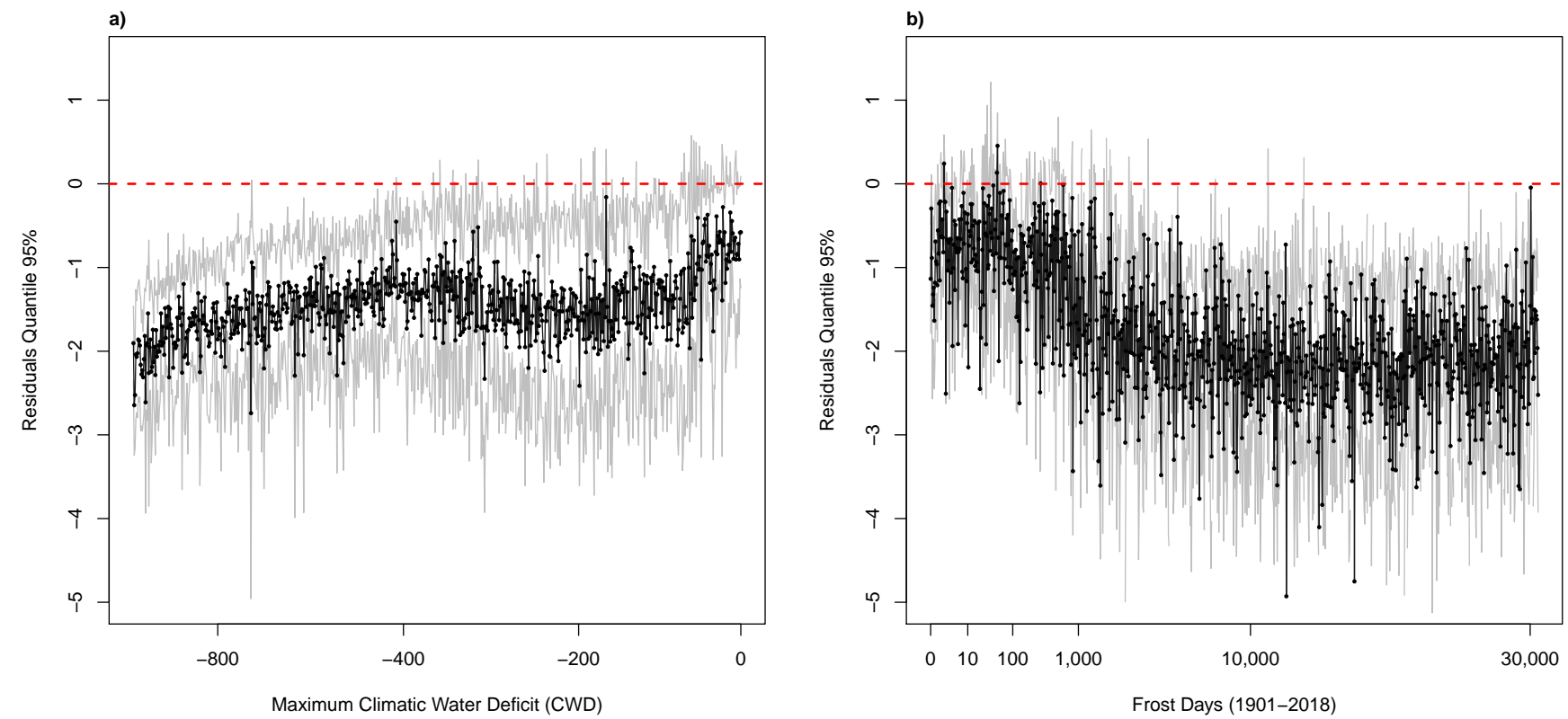

Fig.5 Distribution of the residuals according to the $95 \%$ quantile fit along two limiting species richness environmental variables: A) the Maximum Climatological Water Deficit, and B) the Number of Frost Days between 1901 and 2018. Black lines connect the points showing the mean values for each ordered category and gray lines connect the points for standard deviation. 


\section{Discussion}

These results show that the kinetic model to mechanistically relate the $\quad{ }_{179}$ variation in species richness with environmental temperature apply to the upper bound of the relationship in a broad scale. Both of the central 180 predictions of the model (i.e., a slope a) linear of b) -0.65) are found at the $95 \%$ quantile of the regression (Table 1, Fig. 1). Two environmental drivers impose constraints to the assemblages in reaching the potential maximum species richness. The greater the water deficit and the number of days with freezing temperatures in a year, the bigger the residual variation of the upper bound model (Fig. 5).

The kinetic hypothesis Allen et al., 2002, Brown et al., 2004 models a limit for the maximum species richness per unit of temperature rather than variation in the mean values. Although later testing of the kinetic hypothesis focused on the temperature-dependent variation in species richness across different environmental arrangements, the original proposal specified that the model works only if other environmental variables (e.g., water availability) are accounted for (Allen et al., 2002, Allen et al., 2007]. In concordance with the original proposal, the results presented here suggest that under the kinetic model, temperature determines an upper bound of variation in species richness (Fig. 1), and that other variables may prevent local assemblages to reach this potential diversity (Fig. 5). In other words, temperature would determine an environmental carrying capacities rather than to drive the observable variation in species richness, and the kinetic hypothesis is actually modeling the variation of such limits. ${ }^{201}$ Thus, under a bounded framework for diversity, the environmental temperature affecting productivity or energy availability should be interpreted as an ecological constraint placing limits to the potential maximum species richness (see Cornell, 2013, Brodie, 2019]).

Considering temperature as an ecological driver of variation in the environmental carrying capacity should have implications on evolutionary biology and other fields of ecology. For example, some broadly used assumptions to estimate diversification rates should be reconsidered. 
Usually, phylogenetic studies use the ratio between clade diversity and $\quad 210$ clade age to estimate diversification rates and do not consider

environmental constraints to diversification (e.g., Magallon and Sanderson, 2001, Nee, 2001, Phillimore et al., 2006]). However, if species richness is environmentally constrained, this ratio will be misleading since diversity is no longer dependent only on time and diversification rate Cornell, 2013. In other examples, community assemblage under a bounded or an unbounded framework should have different rules. If diversity is bounded by ecological constraints, or if ecological constraints are at least slowing diversification, then asymptotic or slowing diversification should be correlated with diminished niche space CCornell, 2013. Thus, a theoretical trajectory to the niche space filling associated with an increasing in both taxonomic and traits diversity should be possible to hypothesize.

The upper bound fit for the kinetic model works at global (i.e., a complete latitudinal gradient in the Americas) but not at the level of biomes. As the results presented here show, a biome-partitioned analysis of the slopes at the upper bound do not fit with the theoretical predictions as a generality (Fig. 2). Therefore, the expectations of a kinetic model refocused in the upper bound should be tested across regions/biomes scales; or, in regional scales, under gradients of temperature with other variables being controlled, as the original proposal suggests Allen et al., 2002. Biomes are evolutionary modules environmentally constrained, with functional identities Mucina, 2019]. Thus, different environmental arrangements are expected to drive the observable variation in diversity within biomes. Instead, the potential maximum species richness expected per temperature is a general expectation and should be tested in broader scales to avoid the regional effect of evolutionary associations between a particular biota and the particular environmental arrangement constraining the distribution of its diversity.

The slopes of temperate biomes fit better than tropical ones to the predictions of the kinetic model for the upper bound (Fig.2). Indeed, the variation of species richness at a global scale is not stationary Hawkins et al., 2003, and temperature is a better predictor towards high latitudes 
(i.e., in temperate biomes) Hawkins et al., 2003, Kreft and Jetz, 2007, Currie et al., 2004, Field et al., 2005. Instead, the species richness variation at low latitudes (i.e., in tropical biomes) would be best predicted by water-availability variables (e.g., actual evapotranspiration and annual rainfall) Hawkins et al., 2003, Kreft and Jetz, 2007, Currie et al., 2004, Field et al., 2005, or biotic factors Ricklefs, 2004, Donoghue, 2008, Wiens, 2011. Under a refocused kinetic model as a predictor of the maximum species richness, those biotic and abiotic factors driving the observable species richness at low latitudes should be interpreted as constraints for the assemblages to reach their potential diversity. A non-stationary pattern of environmental drivers should also be expected to drive the observable variation in low latitudes. For example, different variables should explain the species richness variation along humidity or elevational gradients. In temperate biomes, temperature would describe better the observable variation in tree-species richness because less environmental arrangement allow the existence of trees. For example, dry environments in high latitudes prevent the existence of trees as a form of life.

Although the slopes of the upper bound kinetic model fit better in temperate biomes (Fig. 2), the distribution of the residuals shows that they are farther away of the model than tropical (wet and dry) ones (Figs. 262 $3,4)$. Therefore, the species richness in temperate biomes follow better the theoretical slope predicted according the variation in environmental temperature, but they are homogeneously constrained by other factor. In other words, a climatic feature (beyond of the relative low environmental temperature) of temperate biomes is preventing the assemblages in reaching the maximum potential species richness. The presence of freezing temperatures in a normal year is a feature of temperate biomes and its effect on the variation of species richness has been largely recognized, even by Alexander Von Humboldt Hawkins, 2001]. As the results presented here show, the distribution of the residual variation driven by the number of days with freezing temperatures shows a pattern like a threshold rather than a gradient (Fig. 5b). While assemblages subject to less than $\sim 10$ days per year with freezing temperatures are close to the model, those 243 244 245 246 247 248 249 250 251 252 253 254 255 256 257 258 259 260 261 263 264 265 266 267 268 269 270 271 272 273 274 275 
assemblages beyond that threshold are homogeneously farther away from $\quad 276$ the upper bound model (Fig. 5b). The effect of freezing temperature on ${ }_{277}$ biodiversity has been detected also in an evolutionary scale, since the best 278 environmental predictor for the evolutionary turnover of tree lineages $\quad 279$ between tropical and extratropical biotas is the presence or absence of $\quad 280$ freezing temperatures in a normal year [Segovia et al., 2020]. Although a 281 putative mechanism for freezing temperatures preventing the assemblages 282 to reach the potential species richness expected by environmental 283 temperature is the cessation of metabolic reactions due to the phase transition associated with freezing water Gillooly et al., 2001, Brown et al., 2004], its effect on the evolutionary scale may be related with eco-evolutionary process associated to the conservative evolution of lineages to inhabit "harsh", non tropical (i.e., dry and/or freezing) environments Currie et al., 2004.Wiens and Donoghue, 2004.

Freezing temperatures and water deficit have been considered among the primary forces shaping plant evolution by acting directly on hydraulic traits |Maherali et al., 2004,Zanne et al., 2014]. Likewise, both of these environmental conditions characterize "harsh", or difficult to colonize, environments, and thus, would explain a decrease in species richness Wiens and Donoghue, 2004]. However, their influence on the variation of the observable species richness work in different ways. While freezing temperatures would cease the temperature-dependent metabolic rate, water deficit may constrain the potential species richness by drop the total number of individuals in a community Gaston, 2000, Enquist and Niklas, 2001, Allen et al., 2002, Allen et al., 2007]. The results presented here show that the slopes in tropical dry biomes are positive rather than negative (Fig. 2). This trend of potential maximum species richness increasing to relatively colder sites within tropical dry environments is expectable because temperature and precipitation may interact in determining the species richness of water-limited biomes. Actually, the increment of water climatic deficit (i.e., the interaction between temperature and precipitation) drives an increase in the residual variation (Fig. 5). Therefore, future works should be careful in separating the

\section{4 285} 286 287 288 289 290 291 292 293 294 295 296 297 298 299 300 301 302 303 304 305 306 307 308 
variation in species richness associated with the total number of individuals 309 per unit of area from those with no changes on this variable, despite 310 evolutionary convergences, and generalizations such as ecological harshness. 311

Changing the focus from the central tendency towards the limits 312 allows for clarifying that the metabolic effect of environmental temperature works on the maximum species richness and, therefore, to conclude that the kinetic hypothesis described a model of the potential maximum species richness variation or the environmental carrying capacity. Instead, the observed variation of species richness is controlled by secondary environmental arrangements in different ways, suggesting that its effect can be spatial or geographically not stationary. The structure of wet-tropics species-rich versus dry-tropics and extratropics species-poor can be driven by processes such different as changes in abundances or evolutionary constraints. Therefore, the attempts to understand the variation of species richness under the framework of the latitudinal gradient should be revisited. A perspective that considers that temperature determines an upper bound and other variables can influence the observable species richness through different mechanism should allow a deeper understanding of the relationship between environments and biodiversity.

\section{Dataset}

The tree assemblages dataset was derived by combining the NeoTropTree (NTT; http://neotroptree.info) database Oliveira-Filho, 2014] and the Forest Inventory and Analysis (FIA) Program of the U.S.

Forest Service Burrill et al., 2018], accessed on March, 2019 via the BIEN package Maitner et al., 2018 for the R Statistical Environment R Core Team, 2018. I excluded from the FIA database any plot that had less than two species. The inventories in the NTT database are defined by a single vegetation type within a circular area with a $5 \mathrm{~km}$ radius and contains records of tree and tree-like species, i.e., freestanding plants with stems that can reach over $3 \mathrm{~m}$ in height (see www.neotroptree.info and Silva de 
Miranda et al. (2018) Silva de Miranda et al., 2018 for details). Each FIA 340 plot samples trees that are $>12.7 \mathrm{~cm}$ diameter at breast height $(\mathrm{dbh})$ in $\quad 341$ four subplots (each being $168.3 \mathrm{~m} 2$ ) that are $36.6 \mathrm{~m}$ apart. I aggregated 342 plots from the FIA dataset in a $10 \mathrm{~km}$ diameter space, to parallel the $\quad 343$ spatial structure of the NTT database. This procedure produced a total ${ }_{344}$ dataset of 10,721 tree assemblages distributed across major environmental 345 and geographic gradients in the Americas. Taxonomic nomenclature was 346 made consistent by querying species names against The Plant List 347 (http://www.theplantlist.org). Mean annual temperature was 348 extracted from the Worldclim dataset Hijmans et al., 2005, the number of ${ }_{349}$ frost days per year was extracted from the Climatic Research Unit's 350 (CRU) Harris et al., 2020, and Maximum Climatological Water Deficit ${ }_{351}$ (CWD) from Chave et al. 2014 Chave et al., 2014 for the coordinates 352 assigned to each tree assemblage.

\section{Statistical Analyses}

Kinetic hypothesis testing: In order to explore the fit of the relationship between the inverse of temperature $(1,000 / \mathrm{kK})$ and the natural logarithm of species richness towards the upper bound, I used Quantile Regressions Koenker and Bassett Jr, 1978 above the mean linear regression (50\%). As quantile regression is insensitive to heteroscedastic errors and dependent variable outliers Koenker and Bassett Jr, 1978, it is useful to explore the prediction of the kinetic hypothesis above the mean values. Indeed, quantile regressions have been previously described as particularly useful in exploratory and inferential analyses concerning limiting factors in ecology Cade et al., 1999, which makes it useful to study the relationship of species richness and temperature towards the upper bound. Thus, I tested the two main predictions derived from the kinetic hypothesis: linearity and a negative slope of -0.65 . 
with "quantreg" Koenker, 2018 and "segmented" Muggeo, 2008 370 packages in R $\mathrm{R}$ Core Team, 2018]. I measured the goodness-of-fit (R1) of 371 each quantile models by estimating the ratio between the sum of absolute ${ }_{372}$ deviations in the fully parameterized models and the sum of absolute 373 deviations in the null (non-conditional) quantile model, following Koenker 374 and Machado, 1999. R1 constitutes a local measure of goodness of fit for a 375 particular quantile rather than a global measure of goodness of fit over the 376 entire conditional distribution, like R2 [Koenker and Machado, 1999]. This 377 estimation was done using the function goodfit from "WRTDStidal" R ${ }_{378}$ package.

In order to define if a linear or a segmented fit is better in each quantile, I 380 used two approaches. First, I compared the models by the Schwartz's 381 Information Criterion (SIC). Second, following Hawkins et al. (2007a) Hawkins et al., 2007a , I tested if both slopes in the segmented model are different from each other using a $t$ test. If the two slopes were not significantly different $(\mathrm{P}>0.05)$, the relationship between rescaled temperature and ln-transformed richness was classified as being linear on the quantile, whereas data sets with significantly different slopes were classified as being nonlinear.

Slope: Brown et al. (2004) Brown et al., 2004 and Allen et al. (2007) Allen et al., 2007 argued that slopes of richness-temperature regressions should fall near $\sim-0.65$. This value is different than the proposed by Allen et al. 2002 Allen et al., 2002 (-0.9) due to later changes in the rescaling transformation. While Allen et al. (2002) used as transformation 1000/K, where K is kelvins, Brown et al. (2004) and Allen et al. (2007) used $1 /(k \mathrm{~K})$, where $k$ is the Boltzman's constant. In order to test this prediction towards the upper bound of the relationship, I simply compared the slopes of all the linear Quantile Regressions, and each segments in segmented Quantile Regressions.

Also, I tested the slopes for the predictions through biomes by splitting the 396 dataset according Olson et al. (2001) ecorregions and biomes Olson et al., ${ }_{400}$ 2001]. I estimated the slopes for the $95 \%$ quantile to tests the predictied ${ }_{401}^{40}$ 
slope in an upper bound model to the kinetic hypothesis for each of the eight main biomes in the Americas.

Residuals Variation: As I found the 95\% quantile regression is the best model to fit the kinetic model for species richness, I explored the spatial distribution and the environmental determinants of the residual variation at this quantile. In order to show the geographic distribution of the 406 residual variation and its relationship with the species richnees, I grouped the residuals in higher than -1.5 (i.e. small residual variation) and lower than -1.5 (i.e. big residual variation). Also I grouped the assemblages by species richness: less than 100 species; between 101 and 200 species; and more than 201 species. Likewise, in order to show the variation in the distribution of residuals across biomes, I plotted the residual variation in a boxplot organized by biomes from Olson et al. (2001) Olson et al., 2001.

Finally, I also tested the variation of the residuals with the variation of Maximum Climatological Water Deficit (CWD) from Chave et al. (2014) Chave et al., 2014 because Allen et al. (2007) Allen et al., 2007 hypothesized that the residual variation on an upper bound fit should be associated with water availability. Alternatively, I evaluated the effect of cumulative frost days from 1901 until 2018, from the Climatic Research Unit's (CRU) Harris et al., 2020 on the residual variation because the frost line has been proposed as an environmental threshold for taxonomic, 422 functional, and evolutionary diversity on trees and, therefore, I 423 hypothesized that it could also affect the relationship between species $\quad{ }_{424}$ richness and mean annual temperature. In order to plot the distribution of ${ }_{425}$ residuals across the continuous environmental variables, I use the function discretize() in the "arules" package [Hahsler et al., 2019] with the "cluster" ${ }_{427}$ method. Thus, I calculated a mean and a standard deviation across the $\quad{ }_{428}$ ordered categories in both of the variables. 
Acknowledgments: CONICYT PIA APOYO CCTE AFB170008. R.A.S. ${ }_{430}$ is supported by a Newton International Fellowship from The Royal Society ${ }_{431}$ and by Conicyt PFCHA/Postdoctorado Becas Chile/2017 N $3140189 . \quad{ }_{432}$ 


\section{References}

Adams and Woodward, 1989. Adams, J. and Woodward, F. (1989). Patterns in tree species richness as a test of the glacial extinction hypothesis. Nature, 339(6227):699.

Algar et al., 2007. Algar, A. C., Kerr, J. T., and Currie, D. J. (2007). A test of metabolic theory as the mechanism underlying broad-scale species-richness gradients. Global Ecology and Biogeography, 16(2):170-178.

Allen et al., 2002. Allen, A. P., Brown, J. H., and Gillooly, J. F. (2002). Global biodiversity, biochemical kinetics, and the energetic-equivalence rule. Science, 297(5586):1545-1548.

Allen et al., 2007. Allen, A. P., Gillooly, J. F., Brown, J. H., et al. (2007). Recasting the species-energy hypothesis: the different roles of kinetic and potential energy in regulating biodiversity. Scaling biodiversity, 1.

Brodie, 2019. Brodie, J. F. (2019). Environmental limits to mammal diversity vary with latitude and global temperature. Ecology Letters, 22(3):480-485.

Brown, 2014. Brown, J. H. (2014). Why are there so many species in the tropics? Journal of Biogeography, 41(1):8-22.

Brown et al., 2004. Brown, J. H., Gillooly, J. F., Allen, A. P., Savage, V. M., and West, G. B. (2004). ${ }_{448}$ Toward a metabolic theory of ecology. Ecology, 85(7):1771-1789.

Burrill et al., 2018. Burrill, E., Wilson, A., Turner, J., Pugh, S., Menlove, J., Christiansen, G., Conkling, B., and David, W. (2018). The Forest Inventory and Analysis Database: database description and user guide version 8.0 for Phase 2. U.S. Department of Agriculture, Forest Service, Available at web address: www.fia.fs.fed.us/library/database-documentation.

Cade et al., 1999. Cade, B. S., Terrell, J. W., and Schroeder, R. L. (1999). Estimating effects of limiting factors with regression quantiles. Ecology, 80(1):311-323.

Chave et al., 2014. Chave, J., Réjou-Méchain, M., Búrquez, A., Chidumayo, E., Colgan, M. S., Delitti, W. B., Duque, A., Eid, T., Fearnside, P. M., Goodman, R. C., et al. (2014). Improved allometric models to estimate the aboveground biomass of tropical trees. Global change biology, 20(10):3177-3190.

Cornell, 2013. Cornell, H. V. (2013). Is regional species diversity bounded or unbounded? Biological Reviews, 88(1):140-165.

Currie, 2007. Currie, D. (2007). Regional-to-global patterns of biodiversity, and what they have to say about mechanisms. Scaling biodiversity, pages 258-282. 
Currie, 1991. Currie, D. J. (1991). Energy and large-scale patterns of animal-and plant-species richness. The American Naturalist, 137(1):27-49.

Currie et al., 2004. Currie, D. J., Mittelbach, G. G., Cornell, H. V., Field, R., Guégan, J.-F., Hawkins, B. A., Kaufman, D. M., Kerr, J. T., Oberdorff, T., O’Brien, E., et al. (2004). Predictions and tests of climate-based hypotheses of broad-scale variation in taxonomic richness. Ecology letters, 7(12):1121-1134.

Currie and Paquin, 1987. Currie, D. J. and Paquin, V. (1987). Large-scale biogeographical patterns of species richness of trees. Nature, 329(6137):326.

Donoghue, 2008. Donoghue, M. J. (2008). A phylogenetic perspective on the distribution of plant diversity. Proceedings of the National Academy of Sciences, 105(Supplement 1):11549-11555.

Enquist et al., 1998. Enquist, B. J., Brown, J. H., and West, G. B. (1998). Allometric scaling of plant energetics and population density. Nature, 395(6698):163-165.

Enquist and Niklas, 2001. Enquist, B. J. and Niklas, K. J. (2001). Invariant scaling relations across tree-dominated communities. Nature, 410(6829):655.

Field et al., 2005. Field, R., O’Brien, E. M., and Whittaker, R. J. (2005). Global models for predicting woody plant richness from climate: development and evaluation. Ecology, 86(9):2263-2277.

Francis and Currie, 2003. Francis, A. P. and Currie, D. J. (2003). A globally consistent richness-climate relationship for angiosperms. The American Naturalist, 161(4):523-536.

Gaston, 2000. Gaston, K. J. (2000). Global patterns in biodiversity. Nature, 405(6783):220.

Gillooly et al., 2001. Gillooly, J. F., Brown, J. H., West, G. B., Savage, V. M., and Charnov, E. L. (2001). Effects of size and temperature on metabolic rate. science, 293(5538):2248-2251.

Hahsler et al., 2019. Hahsler, M., Buchta, C., Gruen, B., and Hornik, K. (2019). arules: Mining Association Rules and Frequent Itemsets. R package version 1.6-3.

Harris et al., 2020. Harris, I., Osborn, T. J., Jones, P., and Lister, D. (2020). Version 4 of the cru ts monthly high-resolution gridded multivariate climate dataset. Scientific data, 7(1):1-18.

Hawkins, 2001. Hawkins, B. A. (2001). Ecology's oldest pattern? Trends in Ecology EG Evolution, 16(8):470.

Hawkins et al., 2007a. Hawkins, B. A., Albuquerque, F. S., Araujo, M. B., Beck, J., Bini, L. M.,

Cabrero-Sañudo, F. J., Castro-Parga, I., Diniz-Filho, J. A. F., Ferrer-Castán, D., Field, R., et al. 
(2007a). A global evaluation of metabolic theory as an explanation for terrestrial species richness 494 gradients. Ecology, 88(8):1877-1888.

Hawkins et al., 2007b. Hawkins, B. A., Diniz-Filho, J. A. F., Bini, L. M., Araújo, M. B., Field, R., ${ }^{496}$ Hortal, J., Kerr, J. T., Rahbek, C., Rodríguez, M. , and Sanders, N. J. (2007b). Metabolic theory ${ }^{497}$ and diversity gradients: Where do we go from here? Ecology, 88(8):1898-1902.

Hawkins et al., 2003. Hawkins, B. A., Porter, E. E., and Felizola Diniz-Filho, J. A. (2003).

Productivity and history as predictors of the latitudinal diversity gradient of terrestrial birds.

Ecology, 84(6):1608-1623.

Hijmans et al., 2005. Hijmans, R. J., Cameron, S. E., Parra, J. L., Jones, P. G., and Jarvis, A.

(2005). Very high resolution interpolated climate surfaces for global land areas. International Journal of Climatology: A Journal of the Royal Meteorological Society, 25(15):1965-1978.

Jetz and Rahbek, 2002. Jetz, W. and Rahbek, C. (2002). Geographic range size and determinants of 505 avian species richness. Science, 297(5586):1548-1551.

Koenker, 2018. Koenker, R. (2018). quantreg: Quantile Regression. R package version 5.38.

Koenker and Bassett Jr, 1978. Koenker, R. and Bassett Jr, G. (1978). Regression quantiles. Econometrica: journal of the Econometric Society, pages 33-50.

Koenker and Machado, 1999. Koenker, R. and Machado, J. A. (1999). Goodness of fit and related inference processes for quantile regression. Journal of the american statistical association, 94(448):1296-1310.

Kreft and Jetz, 2007. Kreft, H. and Jetz, W. (2007). Global patterns and determinants of vascular plant diversity. Proceedings of the National Academy of Sciences, 104(14):5925-5930.

Magallon and Sanderson, 2001. Magallon, S. and Sanderson, M. J. (2001). Absolute diversification rates in angiosperm clades. Evolution, 55(9):1762-1780.

Maherali et al., 2004. Maherali, H., Pockman, W. T., and Jackson, R. B. (2004). Adaptive variation in the vulnerability of woody plants to xylem cavitation. Ecology, 85(8):2184-2199.

Maitner et al., 2018. Maitner, B. S., Boyle, B., Casler, N., Condit, R., Donoghue, J., Durán, S. M., 519 Guaderrama, D., Hinchliff, C. E., Jørgensen, P. M., Kraft, N. J., et al. (2018). The bien r package: 520 A tool to access the botanical information and ecology network (bien) database. Methods in Ecology and Evolution, 9(2):373-379.

Mucina, 2019. Mucina, L. (2019). Biome: evolution of a crucial ecological and biogeographical concept. New Phytologist, 222(1):97-114. 
Muggeo, 2008. Muggeo, V. M. (2008). segmented: an r package to fit regression models with broken-line relationships. $R$ News, 8(1):20-25.

Mutke and Barthlott, 2005. Mutke, J. and Barthlott, W. (2005). Patterns of vascular plant diversity ${ }^{527}$ at continental to global scales. Biologiske skrifter, 55(4):521-531.

Mutke et al., 2001. Mutke, J., Kier, G., Braun, G., Schultz, C., and Barthlott, W. (2001). Patterns of african vascular plant diversity: A gis based analysis. Systematics and Geography of Plants, pages $1125-1136$.

Nee, 2001. Nee, S. (2001). Inferring speciation rates from phylogenies. Evolution, 55(4):661-668.

O’Brien, 1998. O’Brien, E. (1998). Water-energy dynamics, climate, and prediction of woody plant species richness: an interim general model. Journal of Biogeography, 25(2):379-398.

O’Brien, 1993. O’Brien, E. M. (1993). Climatic gradients in woody plant species richness: towards an explanation based on an analysis of southern africa's woody flora. Journal of Biogeography, pages 181-198.

Oliveira-Filho, 2014. Oliveira-Filho, A. (2014). Neotroptree, flora arbórea da região neotropical: Um banco de dados envolvendo biogeografia, diversidade e conservação. Belo Horizonte: Universidade Federal de Minas Gerais.

Olson et al., 2001. Olson, D. M., Dinerstein, E., Wikramanayake, E. D., Burgess, N. D., Powell, G. V., Underwood, E. C., D'amico, J. A., Itoua, I., Strand, H. E., Morrison, J. C., et al. (2001). Terrestrial ecoregions of the world: A new map of life on eartha new global map of terrestrial ecoregions provides an innovative tool for conserving biodiversity. BioScience, 51(11):933-938.

Phillimore et al., 2006. Phillimore, A. B., Freckleton, R. P., Orme, C. D. L., and Owens, I. P. (2006). 545 Ecology predicts large-scale patterns of phylogenetic diversification in birds. The American Naturalist, 168(2):220-229.

R Core Team, 2018. R Core Team (2018). R: A Language and Environment for Statistical Computing. R Foundation for Statistical Computing, Vienna, Austria.

Ricklefs, 2004. Ricklefs, R. E. (2004). A comprehensive framework for global patterns in biodiversity. 550 Ecology letters, 7(1):1-15.

Rohde, 1992. Rohde, K. (1992). Latitudinal gradients in species diversity: the search for the primary cause. Oikos, pages $514-527$.

Segovia et al., 2020. Segovia, R. A., Pennington, R. T., Baker, T. R., De Souza, F. C., Neves, D. M., 554 Davis, C. C., Armesto, J. J., Olivera-Filho, A. T., and Dexter, K. G. (2020). Freezing and water 555 
availability structure the evolutionary diversity of trees across the americas. Science Advances, $\quad 556$ 6(19):eaaz5373.

Silva de Miranda et al., 2018. Silva de Miranda, P. L., Oliveira-Filho, A. T., Pennington, R. T.,

Neves, D. M., Baker, R., T., and Dexter, K. G. (2018). Using tree species inventories to map

biomes and assess their climatic overlaps in lowland tropical South America. Global ecology and biogeography, 27(8):899-912.

Stephenson, 1990. Stephenson, N. L. (1990). Climatic control of vegetation distribution: the role of the water balance. The American Naturalist, 135(5):649-670.

Wiens and Donoghue, 2004. Wiens, J. and Donoghue, M. (2004). Historical biogeography, ecology and species richness. Trends in ecology \& evolution, 19(12):639-644.

Wiens, 2011. Wiens, J. J. (2011). The causes of species richness patterns across space, time, and clades and the role of "ecological limits". The Quarterly Review of Biology, 86(2):75-96.

Zanne et al., 2014. Zanne, A. E., Tank, D. C., Cornwell, W. K., Eastman, J. M., Smith, S. A., 